\title{
The PAN Study: The First Step into the Future
}

\section{Die PAN-Studie - der erste Schritt in die Zukunft}

T. Paul

Affiliation

Department of Pediatric Cardiology and Pediatric Intensive Care Medicine, University Hospital, GeorgAugust-University, Göttingen, Germany

\section{Bibliography}

DOI http://dx.doi.org/ 10.1055/s-0030-1263147

Klin Padiatr 2010; 222: 281

(c) Georg Thieme Verlag KG

Stuttgart · New York

ISSN 0300-8630

\section{Correspondence}

\section{Thomas Paul, MD}

Department of Pediatric Cardiology and Intensive Care Medicine

University Hospital Georg-August-University

Robert-Koch-Straße 40

37075 Göttingen

Germany

Tel.: +49/551/396 203

Fax: + 49/551/392 2561

tpaul@gwdg.de
Lindinger et al. published in this issue of Klinische Pädiatrie the data of a new nationwide registry for newborns with congenital heart defects [3]. The so called PAN-study needs to be mentioned from different views as it is important not only for pediatric cardiologists but for all physicians involved in the care of pediatric patients with congenital heart defects and to built up an interdisciplinary network [2]. Furthermore it provides for the first time epidemiological data on the prevalence of congenital heart defects from a nation wide approach. This registry will substantiate the data from previous registries applying different methods $[1,5]$. In the era of transthoracic echocardiography being readily available in Germany for almost every newborn with a suspected congenital heart defect, the prevalence of congenital heart defects was $1.08 \%$ which is higher at the extent of the mild forms [4].

Probably the prevalence for congenital heart diseases may increase furthermore if a highly efficient nationwide postnatal screening program will be introduced. For example Tautz et al. report in this issue on non-invasive peripheral oxygen saturation assessment in 3364 term neonates, carried out at $6-36 \mathrm{~h}$ of age. They detected 9 congenital heart defects that had not been recognized prenatally by routine echocardiography [6]. Only half of these children were found to have other anomalies at the clinical examination. Otherwise, one neonate with coarctation of the aorta and one with pulmonary stenosis were missed in the screening program, with pulse oximetry saturation levels $>95 \%$. In addition neonatal infections have been detected by this screening in 7 newborns.

The methods applied in this nation wide PANstudy are state-of-the-art avoiding duplicate registration in at least $97.5 \%$ of severe and $>95 \%$ of moderate types of congenital heart defects. The following years will show, how underreporting will be excluded; $>90 \%$ of newborns with congenital heart defects born during the study period should be enrolled.

It is of note that only $12.1 \%$ of all congenital heart defects had been detected by fetal echocardiography while the prenatal detection rate was highest for severe lesions as univentricular hearts and Ebstein's anomaly. Facing the fact, that detai- led ultrasonographic screening is offered in every pregnancy, these data should alert physicians and health care providers in order to improve the quality of prenatal diagnostics.

Several limitations need to be addressed that, however, do not impair the strength of the study. The PAN study probably underestimates the true prevalence of heart defects as embryos and fetuses with a lethal defect that precluded birth are not included due to the study design. The same is true for pregnancies which were terminated for a severe cardiac defect of the fetus. On the other end of the spectrum, subclinical defects such as bicuspid aortic valve have most probably not been included into the registry.

This is the report from the first year of data acquisition and it is to be expected that the ongoing PAN study will confirm the data and that it will provide a basis for future studies. Follow-up data for example on outcome are, therefore, not available.

Finally, besides the authors of this report, all pediatricians and pediatric cardiologists involved in the care of babies with congenital heart defects in our country should be acknowledged for their tremendous efforts to realize this first nation wide registry which may serve as a benchmark for other countries when the structure of the care of pediatric heart patients is discussed.

\section{References}

1 Ferencz C, Rubin JD, Loffredo CA et al. Epidemiology of congenital heart disease: the Baltimore-Washington infant heart study 1981-1989. Mount Kisco, NY, Futura; 1993

2 Göbel U, Kontny U, Gortner L et al. Networking in Pediatrics and the Journal's View. Klin Padiatr 2009; 221: 131-133

3 Lindinger A, Schwedler G, Hense HW. Prevalence of congenital heart defects in newborns in Germany: Results of the first registration year of the PAN Study (July 2006 to June 2007). Klin Padiatr 2010; 222: 321-330

4 Martin GR, Perry LW, Ferencz C. Increased prevalence of ventricular septal defect; epidemic or improved diagnosis? Pediatrics 1989; 83: 200-203

5 Pradat P, Francannet C, Harris JA et al. The epidemiology of cardiovascular defects, part I: a study based on data from three large registries of congenital malformations. Pediatr Cardiol 2003; 24: 195-221

6 Tautz J, Merkel C, Loersch F et al. Implication of Pulse Oxymetry Screening for Detection of Congenital Heart Defects. Klin Padiatr 2010; 222: 291-295 